\title{
Retraction Note to: Marine climate prediction based on satellite remote sensing and landscape design of green space in coastal areas
}

\author{
Zhongxia Luo ${ }^{1}$
}

Published online: 23 November 2021

(c) Saudi Society for Geosciences 2021

Retraction Note to: Arabian Journal of Geosciences (2021) 14: 476 https://doi.org/10.1007/s12517-021-06789-x

The Editor-in-Chief and the Publisher have retracted this article because the content of this article is nonsensical. The peer review process was not carried out in accordance with the Publisher's peer review policy. The author has not responded to correspondence regarding this retraction.

The original article can be found online at https://doi.org/10.1007/ s12517-021-06789-x.

Zhongxia Luo

HULUOBO2020@126.com

1 School of Arts, Anhui Polytechnic University,

Wuhu 241000, Anhui, China 